\title{
Visualizing the critique: Strengthening quantitative reasoning skills through design
}

\section{Weinstein, Kathryn ${ }^{\text {a }}$}

${ }^{a}$ Art Department, Queens College, City University of New York, United States

\begin{abstract}
In the age of "Big Data," information is often quantitative in nature. The ability to analyze information through the sifting of data has been identified as a core competency for success in navigating daily life and participation in the contemporary workforce. This skill, known as Quantitative Reasoning $(Q R)$, is characterized by the ability to integrate arithmetic, statistics, visualizations and models for the analysis and interpretation of information. For students intending to pursue careers in graphic design, QR competencies are essential for the design of effective visual displays of information.

This case study provides design educators with an assignment they can use to introduce students to data analytics and visualization strategies. The study describes how, in two sections of an undergraduate Information Design course, the final critique of a mid-term project was replaced with an anonymous survey instead of the traditional delivery of feedback through verbal dialogue. Responses were collated, stripped of identifiers, and distributed to the class with directions to create data visualizations of the critique.
\end{abstract}

The study reveals the potential of the assignment to strengthen the role of students as active participants in the feedback process, clarify the criteria for assessment, and deliver focused feedback to improve student work.

Keywords: Quantitative Reasoning; information design; graphic design; pedagogy; data visualization; design critique. 


\section{Introduction}

All (students) should be able to use simple math tools to reason-to understand, interpret, critique, debunk, challenge, explicate, and draw conclusions. In short, college graduates should be able to evaluate the crush of quantitative data modern life throws at all literate citizens. (Simpson, 1999, p. 2)

This paper presents a case study of a modified critique process that was introduced midway through an Information Design course (Fall 2013 and Spring 2015) taught in an undergraduate graphic design program. For the third and final critique of a midterm project, an anonymous survey replaced the traditional verbal group critique. Data from the surveys were collated into sets for each student project, stripped of identifiers and distributed to the class with instructions to create data visualizations of the survey results. Visualizing the Critique is an assignment that design educators can utilize to facilitate student understanding of Quantitative Reasoning (QR) though the collection, analysis, and visualization of data.

\subsection{Background}

Research has documented a widespread quantitative literacy gap throughout the United States (Kutner, Mark et al., 2007), resulting in leading educational associations and policymakers ${ }^{1}$ identifying QR as a primary learning outcome for $21^{\text {st }}$ century undergraduate education. $\mathrm{QR}^{2}$ is characterized by the ability to integrate arithmetic, statistics, visualizations and models (formulas, graphs, tables and schematics) in the analysis and interpretation of quantitative information (Mathematics Association of America, 2015).

Quantification, a process that requires conceptualization and reconceptualization in relation to the object (or phenomenon) being quantified, is a leap from the tangible to the abstract and back to the tangible, or from context to determination of equations and back to context (Thompson, 2012). QR is characterized by two attributes applied to the quantification process: first, a comfort level with numbers that enables an individual to cope with the practical demands of life; and second, some appreciation and understanding of information which is presented in mathematical terms (Cockcroft, 1992). Applications may be as mundane as calculating a tip as a percentage of a bill or as sophisticated as the ability to draw conclusions about race and poverty from tables of unemployment rates.

QR has no specific locus in college degree programs and often is mistakenly assumed to fall within the discipline of mathematics. In fact, undergraduate introductory courses in

\footnotetext{
1 Association of American Colleges \& Universities (AAC\&U); Lumina Foundation's Degree Qualifications Profile; Western Association of Schools and Colleges (WASC) Senior College and University Commission.

2 Also referred to as Quantitative Literacy or Quantitative Fluency.
} 
mathematics tend to focus on abstractness and specialized language whereas QR, by definition, is a broad set of practical skills (Davidson \& McKinney, 2001) and anchored in real-world data within a specific context (Steen, 2009).

Graphic design programs, often presumed to be a safe haven for math-phobic students, may prove to be one pedagogic space for the development and refinement of QR skills at the undergraduate level. Graphic designers, specifically information designers, are charged with the task of giving visual form to data to produce visualizations of statistical data to reveal patterns and relationships that would not be easily ascertained without the aid of visual representation (Meirelles, 2013). Reducing frustration and promoting the understanding of complex information is the ultimate goal of information design. The challenge of translating data to a new visual language, often employing metaphor and semiotics in the process, requires designers to possess a degree of fluency with numeracy.

\subsection{Context}

Queens College is one of the senior colleges of the City University of New York (CUNY). The college offers a Bachelor of Science degree in Graphic Design, with upwards of 300 declared majors (Queens College, 2015). Information Design, an upper-division design elective offered every third semester, explores the display of information and introduces strategies for designing effective visual communications appropriate for various users, audiences, and platforms. The course integrates lectures and exercises designed specifically to build QR competencies, including: review of mathematical equations for the calculation of fractions and percentages; an overview of statistical literacy; retrieval and analysis of data tables; and graphing and mapping methodologies.

Fourteen students were enrolled in Information Design, Fall 2013 and 16 were enrolled Spring 2015. A diagnostic quiz ${ }^{3}$ to gauge student abilities to calculate fractions, percentages and basic graphing techniques was administered on the first day of class. Only two students from the Fall 2013 and five students from Spring 2015 could successfully answer all of the diagnostic quiz questions.

3 Diagnostic Quiz

1. If $1 / 4 "=.25 ", 1 / 8 "=$ ?

2. If 18 out of 22 students have brown eyes, what is the percentage of brown-eyed students in the class? What is the percentage of non-brown-eyed students?

3. Create a graph of last week's temperatures (F): Mon (!0); Tues (15); Wed (15); Thur (15); Fri (25); Sat (15); Sun (10)

4. Create a graph of last week's range of temperatures (F): Mon (5, 15); Tues (10, 20); Wed (-5,10); Thur (10, 20); Fri (10, 30); Sat $(5,20)$; Sun $(5,15)$

5. Create a graph that shows Company ABC's profits (in millions) from 2007-2010. 2007 (5); 2008 (2.5); 2009 (-2); 2010 (3)

6. Create a graph that compares Company XYX's profits (in millions) with Company ABC's profits from 2007-2010. 2007 (2.5); 2008 (5); 2009 (1); 2010 (5). 


\subsection{The Design Critique}

The design critique is a widely used assessment tool in design studio classes and arguably the single most consistently employed classroom activity students encounter in an undergraduate design program. Traditionally, the critique consists of project presentations at various stages of completion, and the subsequent verbal feedback is provided through peers, teachers, and invited guest critics. A basic tenet of the critique is that the individual and the group benefit from the process; students demonstrate an understanding of design principles and strategies through their work and through the questions, comments, and ensuing dialogue. The objective of the process is to create a collaborative environment that facilitates the development of design and presentation skills and provides a means to gauge success for a particular project.

Schrand and Eliason's (2012) research indicates that the design critique does not always allow all types of students to participate, and students who are not confident enough to ask questions are left behind. Barrett (2000) and Percy (2004) cite frustration, alienation, and lack of student participation as outcomes of the traditional design critique. Further research yields a list of factors that may impede student learning, including the size (Blair, 2006) and dynamics of the group (Gray, 2013); language and cultural competencies (Lasserre, 2010; Wong 2011); and perceived self-efficacy (Gaffney, 2011).

\section{The Assignment: Visualizing the Critique}

For the third and final critique of a midterm project, the traditional critique was replaced with a nonverbal assessment and developed into a fourth class assignment, Visualizing the Critique. Like a traditional critique, the activity began with students pinning their work to the display board for the group to assess. A survey with questions regarding research, originality of topic and solution, and the relative success of each project was distributed for the review of students' projects. Students were encouraged to ask questions to clarify the survey questions, but were instructed to refrain from verbally commenting on the projects or leaving any identifying information on the surveys. After the completion and collection of a set of surveys, the group repeated the process for each midterm project.

The teacher collected and collated the sets of surveys, generating a numbering system to identify the projects to minimize the possibility of identification of individuals with survey responses.

Data sets for the collated surveys were distributed to students the following week with a group discussion on the method of collection, and assessment of the quality of the data and a short lecture on normal (Gaussian) distribution. The next step required students to create a data visualization of the collected data. Upon completion of the assignment, students were privately informed of which data set was associated with each of their midterm projects. 


\section{Results}

Table 1 shows the raw data distributed to students from the Fall 2013 survey exercise. The options for response to the questions were yes $(\mathrm{Y})$, no $(\mathrm{N})$, or no answer (NA). Nine midterm projects were presented and 13 students participated in the survey exercise in Fall 2013. A similar data set was distributed to Spring 2015 students. ${ }^{4}$ Class discussions on the quality of the data, possible anomalies and the impact of sample size accompanied the distribution of the survey results.

Table 1. Fall 2013 Information Design Survey Responses.

\begin{tabular}{cccccccccc}
\hline & Q1 & Q2 & Q3 & Q4 & Q5 & Q6 & Q7 & Q8 & Q9 \\
& Y(N)NA & Y(N)NA & Y(N)NA & Y(N)NA & Y(N)NA & Y(N)NA & Y(N)NA & Y(N)NA & Y(N)NA \\
\hline P1 & $3(7) 3$ & $5(3) 5$ & $10(-) 3$ & $9(1) 3$ & $1(7) 5$ & $2(6) 5$ & $4(7) 3$ & $6(5) 2$ & $2(7) 4$ \\
P2 & $9(3) 2$ & $6(5) 2$ & $10(1) 2$ & $7(3) 3$ & $3(6) 4$ & $6(4) 3$ & $3(10)-$ & $9(2) 2$ & $4(7) 2$ \\
P3 & $6(6) 1$ & $3(9) 1$ & $10(1) 2$ & $9(3)-$ & $3(9)-$ & $-(10) 3$ & $6(5) 2$ & $10(2) 1$ & $4(8) 1$ \\
P4 & $11(2) 1$ & $7(4) 2$ & $13(-)-$ & $11(1) 1$ & $2(7) 3$ & $6(5) 2$ & $8(4) 1$ & $12(1)-$ & $4(8) 1$ \\
P5 & $6(7)-$ & $-(12) 1$ & $10(2) 1$ & $4(8) 1$ & $2(11)-$ & $9(3) 1$ & $-(12) 1$ & $4(9)-$ & $3(8) 2$ \\
P6 & $8(2) 3$ & $6(4) 3$ & $10(1) 2$ & $9(1) 3$ & $3(4) 6$ & $5(6) 2$ & $7(2) 4$ & $9(1) 3$ & $6(3) 4$ \\
P7 & $6(6) 1$ & $2(9) 2$ & $10(1) 2$ & $9(3)-$ & $3(10)-$ & $1(10) 2$ & $6(5) 2$ & $10(2) 1$ & $4(8) 1$ \\
P8 & $13(-)-$ & $11(2)-$ & $12(1)-$ & $12(1)-$ & $6(7)-$ & $5(5) 3$ & $7(4) 2$ & $13(-)-$ & $12(1)-$ \\
P9 & $13(-)-$ & $12(1)-$ & $13(-)-$ & $13(-)-$ & $6(4) 3$ & $10(2) 1$ & $11(3)-$ & $10(2) 1$ & $10(2) 1$ \\
\hline
\end{tabular}

Source: Data collected during an Information Design class (November 2013). Nine students presented midterm projects. Thirteen students completed surveys. Q1. Is the topic original? Q2. Is the project ambitious? Q3. Is the designer interested in the project? Q4. Did the designer research the project? Q5. Did the designer explore multiple solutions? Q6. Is the solution original? Q7. Is the project well designed (consider use of color, typography, hierarchy)? Q8. Does the project capture your interest? Q9. Does the project require you to think?

Figure 1 shows six solutions to the assignment. Student efforts reveal a wide array of solutions and the ability to visualize data through the use of graphs, charts, and diagrams.

\footnotetext{
4 In this section of Information Design (Spring 2015), 12 students presented midterm projects and 12 students participated in the survey. Two questions were added in the the Spring 2015 survey to distinguish use of color and typography in student projects.
} 


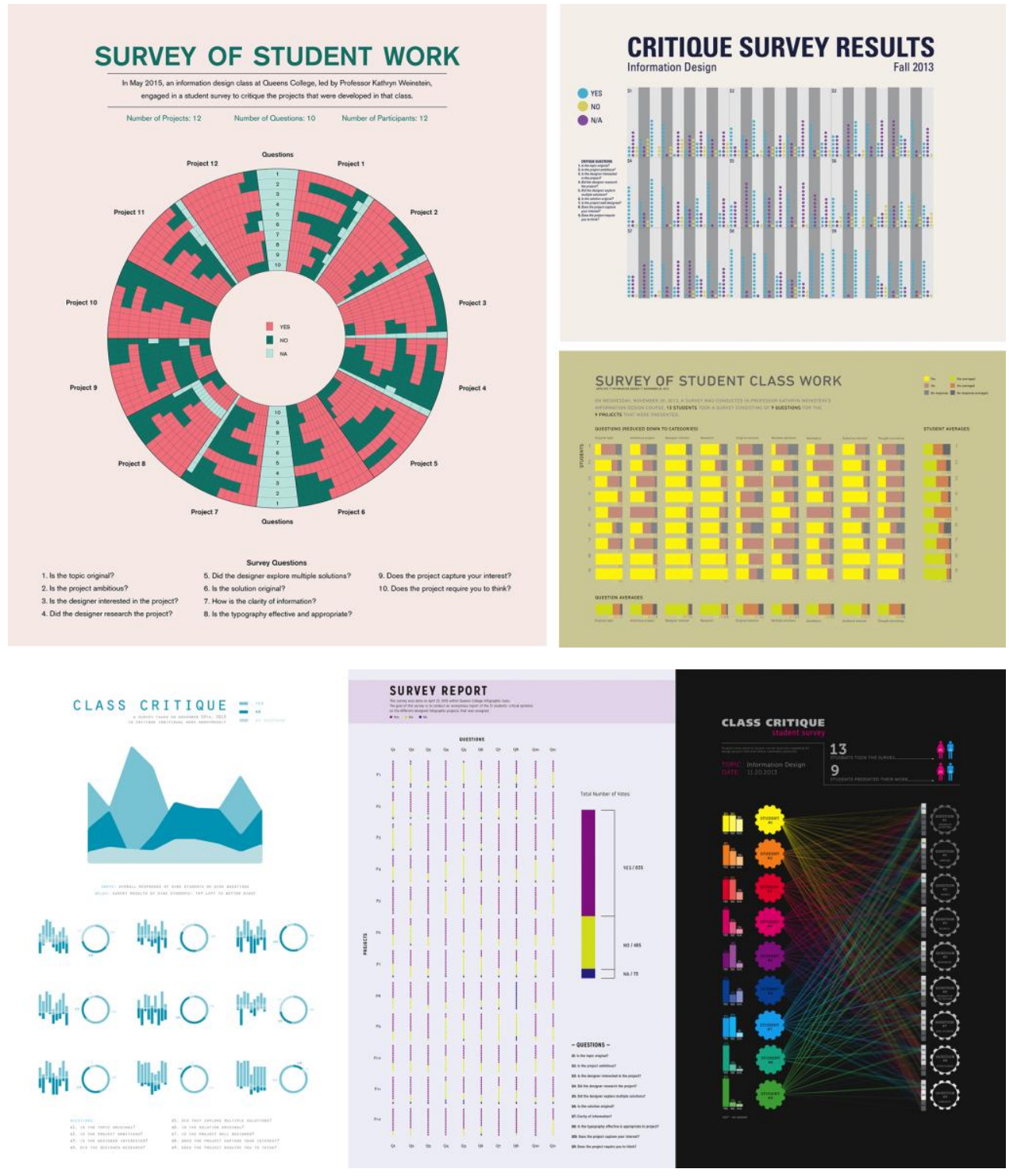

Figure 1. Student responses to visualizing the Critique assignment. Top Row: Samiah Meah, Spring 2016 (left); Madison Chajon, Fall 2013 (top right); Praveena Persuad, Fall 2013 (bottom right).

Bottom Row: Serom Lee, Fall 2013 (left), Qiong Lin, Spring 2015 (center); Elena Akulova, Fall 2013 (right).

\section{Conclusion}

The assignment, Visualizing the Critique, introduces students to data collection and analysis in an area in which all students possess a degree of authority: critiquing one another's projects. The assignment provides an opportunity for students to participate in the 
collection of data and question the methodology and integrity of the data collected, and then proceed to work with collected data and decide how best to visually represent the information. This process requires students to navigate from the tangible (survey results) to the abstract (determination of equations) and back to a tangible (visual presentation of the data).

The projects created for the assignment demonstrate a wide range of solutions and a variety of lenses through which the data may be assessed. Since the introductory diagnostic quiz of the course nine weeks earlier, students demonstrated an increased 'at homeness with numbers' as evidenced by student ease in the calculation of fractions and percentages; the reading and formatting of tables; and the development of mapping and graphing strategies. The verbal critique of the assignment revealed a shifting of priorities when evaluating work, placing coherence and accuracy over aesthetics. Students were quick to point out flaws in equations or mapping techniques and equally quick to praise effective and innovative approaches to the displays of information. In short, Visualizing the Critique provides an assignment that scaffolds skills learned from previous exercises and provides a format for students to demonstrate the refinement of QR skills.

Further, Visualizing the Critique provides teachers with a tool to democratize the critique process. In addition to the traditional forms of design critique, the survey provides a venue for students who typically refrain from verbal exchange in a group setting to express their opinions. All opinions are recorded and carry equal weight, fostering a sense of contribution and participation. The student work and the ensuing critiques throughout the remainder of the semester seemed to be energized by the survey experiment, as demonstrated by a greater degree of verbal participation from all students without prompting and a greater range of opinions confidently expressed. Further research is recommended to assess whether surveys as a pedagogic tool generate a bridge for design students who are typically left out of traditional critiques, and whether this newly found engagement is sustained in new classroom environments.

The specificity of the responses to survey questions may provide students with an effective feedback loop that is obscured through the traditional process of verbal critique. Both the act of responding to a consistent set of questions and that of receiving itemized responses of the survey reinforce the criteria of a project and highlight the areas of success or needed improvement per student. For students who have plunged into the sea of design and are at risk of drowning before they learn to swim, the survey may be one of a set of tools that can demystify the process of design and provide a detailed measure of individual progress.

\section{References}

Association of American Colleges and Universities. 2007. College Learning for the New Global Century: A Report from the National Leadership Council for Liberal Education 
and America's Promise. Washington, DC. Accessed November 28, 2015. http://www.aacu.org/leap/documents/GlobalCentury_final.pdf

Barrett, T. (2000). Studio critiques of student art: As they are, as they could be with mentoring. Theory into Practice, 39(1), 29-35.

Blair, B. (2006). At the end of a huge crit in the summer, it was "crap" - I'd worked really hard but all she said was "fine" and I was gutted. Art, Design \& Communication in Higher Education, 5(2), 83-95.

Cockcroft, W. (1982). Mathematics counts: Report of the Committee of Inquiry into the Teaching of Mathematics in Schools. London: hmso. Pg10-11.

Gaffney, A. L. (2011). Measuring students' self-efficacy for communication. International Journal of Art \& Design Education, 30(2), 211-225.

Davidson, M., and McKinney, G. (2001). Quantitative reasoning: an overview. Dialogue, (8) 1-5. Retrieved July 16, 2015 from http://www.wwu.edu/vpue/documents/issue8.pdf.

Gray, C. M. (2013). Informal peer critique and the negotiation of habitus in a design studio. Art, Design \& Communication in Higher Education, 12(2), 195-209.

Kutner, M., Greenberg E., Jin, J., Boyle, B., Hsu, Y., Dunleavy. E., \& White, S.(2007). Literacy in everyday life: Results from the 2003 national assessment of adult literacy. Institute of Education Sciences National Center for Education Statistics. Washington, DC: United States Department of Education, 286-367.

Lasserre, B. (2010). Speaking the critique in graphic design: The role of metaphor. Art, Design \& Communication in Higher Education, 10(1), 51-66.

Mathematical Association of America. (2015). Quantitative reasoning for college graduates.. Retrieved December 12, 2015 from http://www.maa.org/programs/facultyand-departments/curriculum-department-guidelines-recommendations/quantitativeliteracy/quantitative-reasoning-college-graduates\#Part2

Meirelles, I. (2013). Design for information: An introduction to the histories, theories, and best practices behind effective information visualizations. Beverly, MA: Rockport. p.11.

Percy, C. (2004). Critical absence versus critical engagement. Problematics of the crit in design learning and teaching. Art, Design \& Communication in Higher Education 2(3), 143-154.

Simpson, C. (1999). Quantitative reasoning (QR) progress report. Bellingham: Office of Institutional Research and Resource Planning, Western Washington University. p. 2.

QC at a Glance, Queens College, CUNY, 2015. Retrieved November 28, 2015 from http://www.qc.cuny.edu/about/Glance/Pages/default.aspx.

Schrand, T., \& Eliason, J. (2012). Feedback practices and signature pedagogies: What can the liberal arts learn from the design critique? Teaching in Higher Education, 17(1), 5162.

Thompson, P.W. (2011). Quantitative reasoning and mathematical modeling. In L. L. Hatfield, S. Chamberlain \& S. Belbase (Eds.), New perspectives and directions for collaborative research in mathematics education WISDOMe Monographs (Vol. 1, pp. 33-57). Laramie, WY: University of Wyoming Press.

Wong, H. L. H. (2011). Critique: A communicative event in design education. Visible Language, 45(3), 222-247. 